INEEL/EXT-99-00924

September 1999

\title{
RELAP5-3D CODE VALIDATION FOR RBMK PHENOMENA
}

\author{
J. E. Fisher
}

L OCKHEED MARTIN 


\title{
RELAP5-3D Code Validation for RBMK Phenomena
}

\author{
James E. Fisher
}

Published September 1999

Idaho National Engineering and Environmental Laboratory Nuclear Systems Analysis Technologies Department Idaho Falls, Idaho 83415

Prepared for the

U.S. Department of Energy

Under DOE Idaho Operations Office

Contract DE-AC07-94ID13223 


\begin{abstract}
The RELAP5-3D thermal-hydraulic code was assessed against Japanese Safety Experiment Loop (SEL) and Heat Transfer Loop (HTL) tests. These tests were chosen because the phenomena present are applicable to analyses of Russian RBMK reactor designs. The assessment cases included parallel channel flow fluctuation tests at reduced and normal water levels, a channel inlet pipe rupture test, and a high power, density wave oscillation test. The results showed that RELAP5-3D has the capability to adequately represent these RBMK-related phenomena.
\end{abstract}




\section{SUMMARY}

This report documents the assessment of the RELAP5-3D code against tests conducted in the Japanese Safety Experiment Loop (SEL) and Heat Transfer Loop (HTL). These tests provide data on selected phenomena that are relevant to RBMK safety analyses. The focus of the present work was in two areas. First, validation of the RELAP5-3D code was conducted using test data for which previous RELAP5/MOD3.2 assessment results are available. These assessment calculations were repeated with RELAP5-3D to determine whether the results were comparable to those previously obtained. Second, code validation calculations were conducted using RELAP5-3D for the SEL High Power Flow Instability Test, a case for which RELAP5/MOD3.2 failed to reproduce the response of the test facility.

The assessment cases covered five phenomena identified as applicable to RBMK designs:

- Density wave oscillation induced by high power transients during forced circulation conditions

- Dryout channel power under low flow conditions

- Flow fluctuations in parallel channels without net coolant flow

- Flow fluctuations in parallel channels under natural circulation flow conditions

- Degraded heat transfer in a single channel induced by an inlet pipe rupture

The major conclusion was that RELAP5-3D has the capabilities to properly represent RBMK phenomena. The results showed that RELAP5-3D was capable of representing CCFL, break flow rates, manometer oscillations, flow pattern-induced oscillations, and other phenomena applicable to RBMK transient analyses. In most cases, the RELAP5-3D predictions were nearly identical to previous assessment results obtained using RELAP5/MOD3.2. The results also demonstrated that RELAP5-3D has the capability to predict the high power instability, or density wave oscillations, although it was necessary to adjust the channel pressure loss distribution to obtain this result. This adjustment was justified based on inconsistency and incompleteness of available data.

The CHF model needs improvement; however, the successful prediction of the density wave oscillation response was not strongly dependent upon the precise prediction of dryout in the channel. Results of nodalization studies, which investigated multiple parallel paths in the high power channel, demonstrated that the fluid was well mixed and therefore a single-pipe (or single path) hydraulic model was adequate to represent the channel flow conditions. 


\section{CONTENTS}

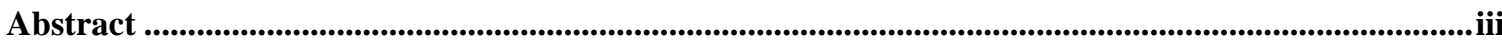

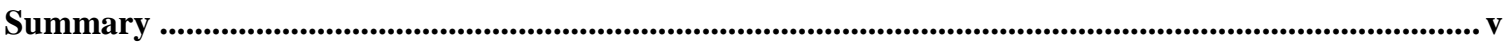

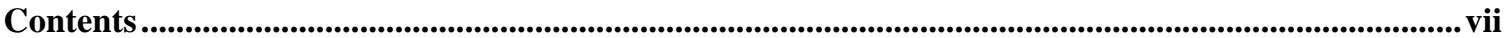

RELAP5-3D Code Validation for RBMK Phenomena......................................................................................... 1

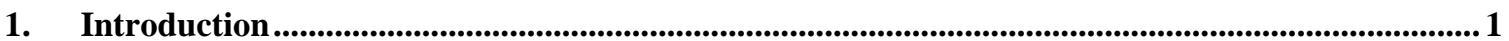

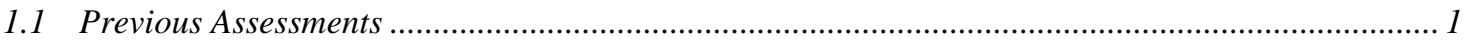

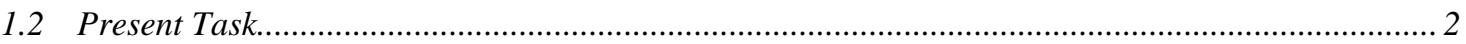

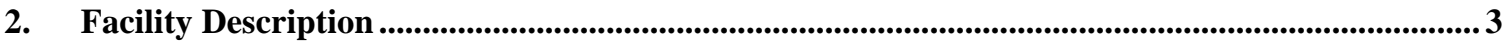

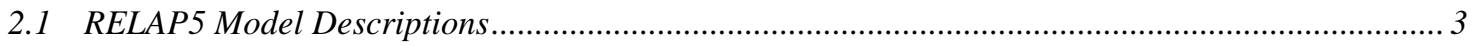

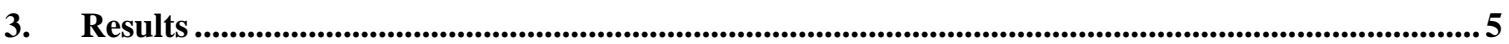

3.1 Comparison of RELAP5-3D and RELAP5/MOD3.2 Assessments................................................ 5

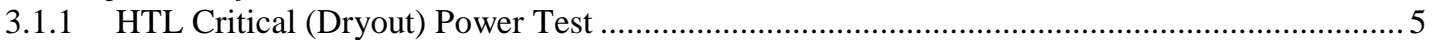

3.1.2 Flow Oscillations Between Parallel Channels at Low Water Levels......................................... 7

3.1.3 Flow Oscillations between Parallel Channels at Normal Water Levels ..................................... 7

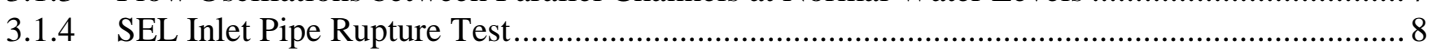

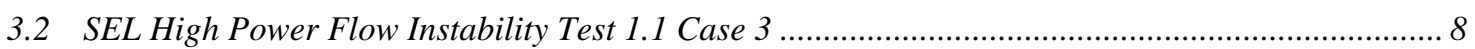

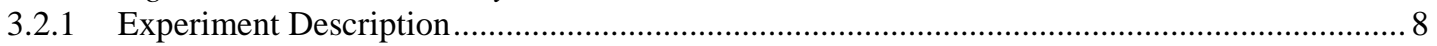

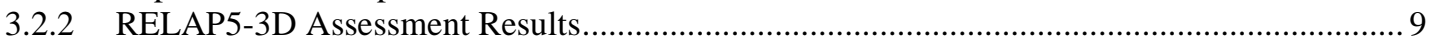

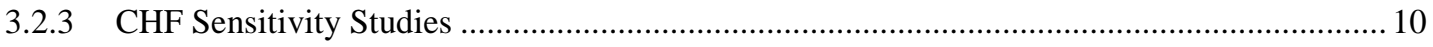

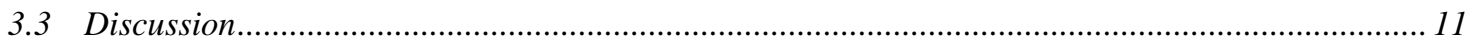

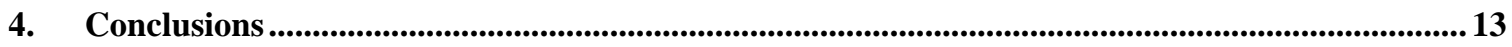

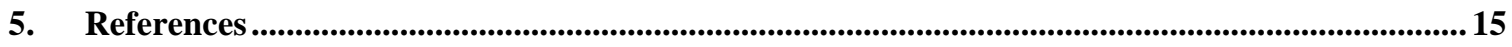

Figure 1. Schematic of Safety Experiment Loop (SEL) facility ...................................................... 17

Figure 2. Schematic of Heat Transfer Loop (HTL) facility.............................................................. 17

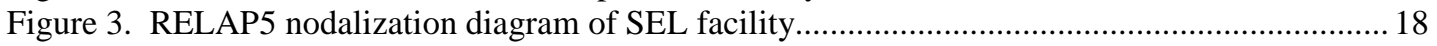

Figure 4. Flow fluctuation in HTL at low water level conditions. ................................................. 19

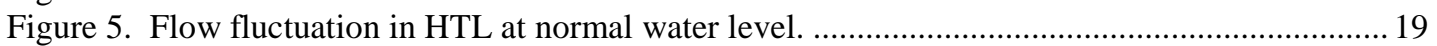

Figure 6. SEL flow responses during inlet pipe rupture test. ............................................................. 20

Figure 7. SEL heater rod surface temperature at elevation 3 during inlet pipe rupture test. ............... 20

Figure 8. SEL and RELAP5 high power channel flowrates during high power flow instability test. . 21

Figure 9. SEL and RELAP5 low power channel flowrates during high power flow instability test...21

Figure 10. SEL and RELAP5 high power channel power during high power flow instability test.....22

Figure 11. Heater rod surface temperatures in upper region of high power channel during high power

flow instability test.

... 22

Figure 12. Heater rod surface temperatures in middle region of high power channel during high 


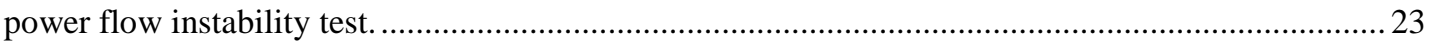

Figure 13. SEL RELAP5 high power channel rod bundle radial ring nodalization. ........................... 23

Figure 14. SEL RELAP5 model high power channel nodalization by geometric similarity ................24 


\section{RELAP5-3D CODE VALIDATION FOR RBMK PHENOMENA}

\section{INTRODUCTION}

The International Atomic Energy Agency (IAEA) has established a project for "Accident Analysis of and Training Programme for the RBMK Kursk 1 NPP", the purpose of which is to upgrade the capability of the host country to perform in-depth safety assessments and reactor safety analyses in general. This project involves transfer of the state of the art computer codes along with associated methodology to ensure that the safety analysis codes and methods are applied correctly.

The project includes requirements for systematic evaluation of the adequacy and applicability of the computer codes to the safety analysis of Soviet-designed reactors. The Japanese Safety Experiment Loop and Heat Transfer Loop tests provide data on selected phenomena relevant to RBMK safety analyses that is available for code validation use.

Validation of the RELAP5-3D code using data from Japanese Safety Experiment Loop (SEL) and Heat transfer (HTL) is the subject of this report. The sections below summarize previous assessments done for the Japanese SEL and HTL tests using an earlier version of the code (RELAP5/MOD3.2), and present the results for the RELAP5-3D assessment of the SEL and HTL tests.

\subsection{Previous Assessments}

Assessments of the SEL and HTL test data have previously been conducted using the RELAP5/MOD3. 2 code. ${ }^{1}$ These assessments covered five areas applicable to RBMK reactor designs:

- Density wave oscillation induced by high power transients during forced circulation conditions

- Dryout channel power under low flow conditions

- Flow fluctuations in parallel channels without net coolant flow

- Flow fluctuations in parallel channels under natural circulation flow conditions

- Degraded heat transfer in a single channel induced by an inlet pipe rupture

The conclusions of these assessments were that RELAP5/MOD3.2 should capture the majority of phenomena important during a small break LOCA in an RBMK. The code showed reasonable results for predicting CCFL, CHF, post CHF heat transfer, and low power flow pattern induced instability. However, good agreement was not achieved for two cases: high power flow instability due to density wave oscillation, and critical tube power (CHF) at low reverse flow. 


\subsection{Present Task}

The focus of the present work was in two areas. First, validation of the RELAP5-3D code was conducted using test data for which previous RELAP5/MOD3.2 assessment results are available. These assessment calculations were repeated with RELAP5-3D to determine whether the results were comparable to the previous results. Second, code validation calculations were conducted using RELAP5-3D for the SEL High Power Flow Instability Test. RELAP5/MOD3.2 was unsuccessful in reproducing the facility response for this test.

The results of the code validation calculations performed using the RELAP5-3D code and the results of the RELAP5-3D assessments of the SEL high power flow oscillations are the two topics of this report. The following sections contain a description of the SEL and HTL facilities, brief descriptions of the associated RELAP5 models, the results of comparison of RELAP5-3D results to previous code validation analyses, and the results of the RELAP5-3D assessment of the high power flow instability test. 


\section{FACILITY DESCRIPTION}

The SEL facility diagram is shown in Figure 1. It consists of 6 parallel heated channels, a steam drum, a circulation pump, a water drum with inlet check valves, and associated piping. Steam water mixtures generated in the heated section flows through the outlet pipes to the steam drum. Each channel contains a full scale electric heater bundle, containing a 36-rod cluster. The SEL has one high power channel capable of producing up to $6 \mathrm{MW}$ and five low power channels capable of producing up to $200 \mathrm{~kW}$ each. Each channel is connected to a lower water drum with a two-inch feeder pipe. For the experiments reported herein, only two heater channels were used, the high power and one low power channel. A shield plug, which simulates a refueling port in an RBMK reactor, is located just above the heater bundle of the high power channel. The long horizontal sections of the outlet pipes to the steam drum have a 2-degree slope. Within the steam drum, turbine separators separate the steam water mixture. The steam is then passed to a condenser that is used to control system pressure. The separated water is mixed with the condensate return from the condenser in the lower portion of the drum and returned via a downcomer to the circulation pump.

Instrumentation available includes the following:

- flow rate measurements at the inlet of each channel

- differential pressure instruments:

- high power channel lower portion

- high power channel upper portion

- high power channel total

- high power channel outlet-to-bottom of shield plug

- $\quad$ shield plug

- $\quad$ top of shield plug-to-steam drum

- $\quad$ water drum-to-steam drum

- electrical heater power measurement for the high and low power channels

- circulating pump rpm

- heater rod surface temperatures in the high power channel

Notably, there is no differential pressure measurement between the water drum and the high power channel inlet. Also, there are no known differential pressure measurements across the low power channel. Thermocouples are located at six elevations in the heated region, numbered from top (1) to bottom (6).

The HTL facility is shown in Figure 2. It is similar to the SEL, but there are a few differences. It has longer outlet piping with 0-degree slope in the long horizontal section. Also there are only two heater channels, which can produce up to $7 \mathrm{MW}$ each. The inlet piping diameter is larger, there is no lower water drum, and the steam drum is smaller. In addition, the HTL has a subcooler in the downcomer and a preheater in the inlet piping, to provide a wide range of inlet subcooling temperatures.

\subsection{RELAP5 Model Descriptions}

The RELAP5 SEL model is shown in Figure 3. It is the same as the one used to conduct RELAP5/MOD3.2 assessment cases reported in Reference 1. It includes all the major 
components that are present in the experiment loop including the high and low power channels, the shield plug in the high power channel outlet, the horizontal outlet piping, the steam drum with moisture separator, the downcomer, recirculating pump, the water drum, and all connecting piping. A check valve is in the model at the inlet to the water drum, corresponding to the physical location in the facility. Additionally, a globe valve is present in each channel inlet line, also corresponding to the actual physical location, and were used to regulate flowrates in the high and low power channels. System pressure is established using a pressure boundary condition at the steam outlet of the steam drum. Heated channel inlet subcooling is established by setting the temperature of the feedwater flow boundary condition in the condenser region of the steam drum. All pipe wall heat structures were modeled, including environmental losses.

The high and low power channel each consisted of a single RELAP5 pipe component with internal node boundaries corresponding to grid spacer locations. The high power channel has 16 axial nodes, and nodes 2 through 13 are heated. Three heat structures are used to model the heated rods in the high power channel, one for the inner 6-rod ring, one for the center 12-rod ring, and one for the outer 18-rod ring. The low power channel also has 16 axial nodes, with nodes 2 through 13 heated. A single heat structure is used to model the entire 36-rod bundle in the low power channel. The physical dimensions of the low power channel are identical to those of the high power channel. This agrees with the available facility information.

The HTL model (nodalization not shown) is similar to the SEL model, with differences that correspond to the differences between the facilities. The heated channels are identical to those in the SEL model, except for differences in grid spacer locations. A single-channel model was used for the assessment of the CHF experiments, and a two-channel model was used for the low power instability tests. 


\section{RESULTS}

\subsection{Comparison of RELAP5-3D and RELAP5/MOD3.2 Assessments}

Table 1 contains a summary of the Japanese SEL and HTL tests that were previously assessed using RELAP5/MOD3.2. The following is a detailed discussion of these assessment cases.

\subsubsection{HTL Critical (Dryout) Power Test}

The HTL Critical Power Test was not simulated using RELAP5-3D. However, the work previously done for the RELAP5/MOD3.2 assessment is briefly described because the results provided a basis for RELAP5 model input that was subsequently used for the SEL High Power Flow Instability Test. This model input consisted of parameters for the Groeneveld CHF correlation that is used to predict the onset of film boiling.

The HTL Critical (Dryout) Power Test consisted of a series of runs conducted in HTL to determine the tube power at which dryout would occur under both upward and downward flow conditions. Only one channel was used in the experiment. Each run was conducted by establishing the desired flow rate in the channel, and increasing power incrementally until dryout was detected. The runs were repeated for different flow rates, covering the range of mass flux from -2000 to $+2000 \mathrm{~kg} / \mathrm{m}^{2} \mathrm{~s}$. The test data were used to set the values of two parameters used in the Groeneveld CHF correlation for the heat structures that represent the heater rods in the high power channel in the RELAP5 model. These parameters are 1) the value of the grid spacer loss coefficient that is input to the $\mathrm{K} 3$ grid spacer factor and 2) the K5 local boiling factor.

First, the grid spacer loss coefficients input to the K3 factors for each heat structure were set to 1.5. These values are the consistent with the values in the hydrodynamic models of HTL and SEL, which, in turn, were set based on data from the SEL Inlet Pipe Rupture test. Second, the local boiling factors K5 were implemented as subchannel correction factors. The values used were based on hand calculations of "subchannel power density" which is the ratio of subchannel power to subchannel flow area normalized to the ratio of the bundle average power to bundle average flow area, i.e.

$$
\frac{\text { Power }_{\text {subchannel }} / \text { Area }_{\text {subchannel }}}{\text { Power }_{\text {average }} / \text { Area }_{\text {average }}}
$$

It was implicitly assumed that there was no subchannel-to-subchannel mixing and that subchannel flowrates were proportional to subchannel flow areas. The K5 factors were therefore applied as hot channel factors. The corrections to the loss coefficients for $\mathrm{K} 3$ and for the $\mathrm{K} 5$ local boiling factors were input to the model to improve the agreement with test results. The results of the assessment are shown in Table 2. As noted, this assessment was not done with RELAP5-3D. However, based on similarity of RELAP5-3D and RELAP5/MOD3.2 results for other HTL and SEL cases, RELAP5-3D assessment results are not expected to be different from the MOD3.2 results. 
Table 1. Previous HTL And SEL test assessment results using RELAP5/MOD3.2.

\begin{tabular}{|c|c|c|c|c|c|}
\hline Facility & Test & Description & Phenomena & Assessment Result & RELAP5-3D Status \\
\hline HTL & $\begin{array}{c}\text { Test } \\
1.2\end{array}$ & $\begin{array}{l}\text { Dryout } \\
\text { channel power } \\
\text { for upward } \\
\text { and downward } \\
\text { flow }\end{array}$ & $\begin{array}{l}\text { CHF } \\
\text { during } \\
\text { upward and } \\
\text { downward } \\
\text { flow }\end{array}$ & $\begin{array}{l}\text { Assessment } \\
\text { performed with } \\
\text { adjusted } \\
\text { Groeneveld CHF } \\
\text { Parameters. Lack } \\
\text { of agreement noted, } \\
\text { particularly at low } \\
\text { flows. Additional } \\
\text { analyses required. }\end{array}$ & $\begin{array}{l}\text { Not Assessed. } \\
\text { Results with } \\
\text { present code should } \\
\text { be no different than } \\
\text { the MOD3.2 } \\
\text { results. }\end{array}$ \\
\hline HTL & $\begin{array}{l}\text { Test } \\
2.1\end{array}$ & $\begin{array}{l}\text { Flow } \\
\text { oscillations } \\
\text { between } \\
\text { parallel } \\
\text { channels at } \\
\text { low water } \\
\text { levels }\end{array}$ & $\begin{array}{l}\text { Manometer } \\
\text { oscillations } \\
\text { between } \\
\text { channels }\end{array}$ & $\begin{array}{l}\text { Code showed good } \\
\text { qualitative } \\
\text { agreement with } \\
\text { data }\end{array}$ & $\begin{array}{l}\text { Reproduces the } \\
\text { MOD3.2 result }\end{array}$ \\
\hline HTL & $\begin{array}{l}\text { Test } \\
2.2\end{array}$ & $\begin{array}{l}\text { Flow } \\
\text { oscillation } \\
\text { between } \\
\text { parallel } \\
\text { channels at } \\
\text { normal water } \\
\text { levels }\end{array}$ & $\begin{array}{l}\text { Flow } \\
\text { pattern } \\
\text { induced } \\
\text { oscillation } \\
\text { at low } \\
\text { power }\end{array}$ & $\begin{array}{l}\text { Code predicted } \\
\text { onset of instability, } \\
\text { but oscillation } \\
\text { amplitude and } \\
\text { frequency were not } \\
\text { matched }\end{array}$ & $\begin{array}{l}\text { Reproduces the } \\
\text { MOD3.2 result }\end{array}$ \\
\hline SEL & $\begin{array}{c}\text { Test } \\
3\end{array}$ & $\begin{array}{l}\text { Degraded heat } \\
\text { transfer } \\
\text { induced by an } \\
\text { inlet pipe } \\
\text { rupture }\end{array}$ & $\begin{array}{l}\text { CCFL, post } \\
\text { CHF heat } \\
\text { transfer, } \\
\text { channel } \\
\text { behavior } \\
\text { under } \\
\text { stagnant } \\
\text { flow } \\
\text { conditions, } \\
\text { reflood }\end{array}$ & $\begin{array}{l}\text { Source of 2-phase } \\
\text { steady state data (6 } \\
\text { seconds) used to set } \\
\text { high power channel } \\
\text { loss coefficients. } \\
\text { Overall transient } \\
\text { response showed } \\
\text { good agreement } \\
\text { with data }\end{array}$ & $\begin{array}{l}\text { Reproduces the } \\
\text { MOD3.2 result } \\
\text { with reflood turned } \\
\text { off. Assessment } \\
\text { using reflood } \\
\text { model not done. }\end{array}$ \\
\hline SEL & $\begin{array}{c}\text { Test } \\
1.1 \\
\text { Case } \\
3\end{array}$ & $\begin{array}{l}\text { Flow } \\
\text { instability } \\
\text { induced by } \\
\text { high power } \\
\text { transients in } \\
\text { parallel } \\
\text { channels }\end{array}$ & $\begin{array}{l}\text { Post dryout } \\
\text { density } \\
\text { wave } \\
\text { oscillations }\end{array}$ & Lack of agreement. & $\begin{array}{l}\text { RELAP5-3D, with } \\
\text { input deck } \\
\text { modifications, } \\
\text { captures the } \\
\text { oscillation. } \\
\text { additional analyses } \\
\text { recommended. }\end{array}$ \\
\hline
\end{tabular}


Table 2. RELAP5 critical power test assessment results.

\begin{tabular}{cc}
\hline $\begin{array}{c}\text { Mass Flux } \\
\left(\mathrm{Kg} / \mathrm{s}-\mathrm{m}^{\wedge} 2\right)\end{array}$ & RELAP5 \\
Gccuracy \\
\hline $0<500$ & $\pm 12 \%$ \\
$-\mathrm{G}<500$ & $\pm 5 \%$ \\
$-500<\mathrm{G}<0$ & "poor" \\
$-750<\mathrm{G}<-500$ & $\pm 15 \%$ \\
$-2000<\mathrm{G}<-1000$ & $\pm 25 \%$ \\
\hline
\end{tabular}

\subsubsection{Flow Oscillations Between Parallel Channels at Low Water Levels}

This experiment was conducted in HTL, with a two-parallel-channel configuration. Heater power levels were 201 and $203 \mathrm{~kW}$. The test was conducted by draining from a normal water inventory until a level approximately $+1 \mathrm{~m}$ above the heated region was reached, at which time a manometer type oscillation was observed between the two channels. Figure 4 compares the volumetric flowrates for channels I and II to the RELAP5-3D results. The channel I comparison is on the left axis of the plot, and the channel II comparison is on the right axis. The characteristics of the oscillation are compared with the RELAP5-3D results in Table 3. As shown, the code predicted the oscillation in a manner similar to the experiment, although RELAP5-3D predicted a lower amplitude and a shorter period than the data. The high and low power channel flowrates were out of phase in the calculation, as in the test. These results are the same, or nearly the same, as those reported in Reference 1.

Table 3. Response characteristics of HTL oscillations at low water levels.

\begin{tabular}{ccc}
\hline & HTL Test 2.1 & RELAP5-3D \\
\hline $\begin{array}{c}\text { Amplitude (standard deviation) } \\
\left(\mathrm{m}^{3} / \mathrm{hr}\right)\end{array}$ & Channel I $=0.78$ & Channel I $=0.34$ \\
Channel II $=1.13$ & Channel II = 0.36 \\
\hline Period (seconds) & $11-13$ & 8 \\
\hline
\end{tabular}

\subsubsection{Flow Oscillations between Parallel Channels at Normal Water Levels}

This experiment was also conducted in HTL with a two-parallel-channel configuration. Heater powers were 227 and $407 \mathrm{~kW}$ in channels I and II, respectively. The nature of the oscillation in this experiment is strongly dependent on the flow pattern in the horizontal portion of the outlet pipes, and is due to discharge of intermittent steam slugs from the horizontal-to-vertical bend. The phenomenon has been confirmed by flow visualization in an air and water test. ${ }^{2}$ Figure 5 compares volumetric flowrate data to the RELAP5-3D response. As with Figure 4, the channel I comparison is on the left axis of the plot, and the channel II comparison is on the right axis. RELAP5-3D predicted the oscillatory response coincident with a flow regime transition between Horizontal Stratified Flow and Slug Flow; however, the channel II power level required was 448 $\mathrm{kW}$ (10\% higher than in the experiment). The predicted oscillatory response was also smaller in magnitude and higher in frequency than in the test. The characteristics of the oscillation are 
compared with the RELAP5-3D results in Table 4. These responses were essentially identical to results previously obtained with RELAP5/MOD3.2 as reported in Reference 1.

Table 4. Response Characteristics of HTL Oscillations at Normal Water Levels.

\begin{tabular}{ccc}
\hline & HTL Test 2.2 & RELAP5-3D \\
\hline $\begin{array}{c}\text { Amplitude (standard deviation) } \\
\left(\mathrm{m}^{3} / \mathrm{hr}\right)\end{array}$ & Channel I $=0.21$ & Channel I $=0.12$ \\
Channel II $=0.26$ & 6 & Channel II $=0.15$ \\
\hline Period (seconds) & 6 & 2.5 \\
\hline
\end{tabular}

\subsubsection{SEL Inlet Pipe Rupture Test}

This test was a 15 -mm pipe break in the high power channel inlet piping. Heater power was reduced to decay heat level after several seconds, and was turned off at 115 seconds. The circulation pump tripped off after $\sim 10$ seconds. The initial six seconds of this test was a quasisteady state period. Differential pressure measurements were not changing rapidly during this time, although the transient was initiated and the break was open. These differential pressure data during this time were used to set high power channel loss coefficients in the RELAP5 input model used for the RELAP5/MOD3.2 assessment reported in Reference 1. The same high power channel loss coefficients were used in the present model, except for modifications done to enable it to reproduce the density wave oscillations. These modifications are discussed in Section 3.3. The simulation was calculated using RELAP5-3D with the reflood model turned off.

Figure 6 compares the volumetric flowrates at the pump outlet line and in the high power channel inlet line (downstream of the break) with the RELAP5-3D responses. As shown, the system flowrates closely matched the data. Figure 7 compares heater rod surface temperature responses of the data and the code. The code generally overpredicted the dryout response for this case; however, the results are considered reasonable. An early departure from nucleate boiling (DNB) event, of approximately 12 seconds duration, was seen beginning at 0.5 seconds in the RELAP53D response. This DNB was not observed in the earlier RELAP5/MOD3.2 assessment, and is attributed to the modeling changes mentioned above. Aside from this difference, the RELAP5$3 \mathrm{D}$ response was the same as for the earlier assessment. The overall transient response predicted by RELAP5-3D showed good agreement with the data.

\subsection{SEL High Power Flow Instability Test 1.1 Case 3}

\subsubsection{Experiment Description}

High Power Flow Instability Test 1.1 included three cases, all of which exhibited the density wave flow oscillation phenomenon. The experiments were conducted at a system pressure of 7 $\mathrm{MPa}$, with low $\left(\sim 1^{\circ} \mathrm{C}\right)$ inlet subcooling. The experiment sequence was as follows. High power channel flowrate was established at the desired value, and the power of the low power heater was held constant at $190 \mathrm{~kW}$. The power of the high power heater was then raised in steps and kept 
constant at each step for about 60 seconds. To compensate for the increased pressure loss characteristics as power was increased, the flow rate was returned to the required value after each power step by adjusting the flow through the recirculating pump.

The RELAP5-3D assessment results completed at this time are only for Case 3 of Test 1.1, the case for which RELAP5/MOD3.2 assessment results were previously reported in Reference 1. The initial conditions in the high power channel for this case were $3.74 \mathrm{~kg} / \mathrm{s}$ flow rate and 3.5 MW power. Power was raised to $4.0 \mathrm{MW}$ at 280 seconds, then to $4.2 \mathrm{MW}$ at 345 seconds. The density wave oscillation was observed at 4.2 MW. Heater power was turned off at 395 seconds, and the test was concluded.

\subsubsection{RELAP5-3D Assessment Results}

Figure 8 compares the flowrate in the high power channel inlet line (designated FRT-2) to the RELAP5-3D calculated value (mass flow rate at junction 120-00). As shown, RELAP5-3D captures the oscillatory response in a reasonable manner, although the peak-to-peak amplitude is about $1 / 3$ lower and the period is about $25 \%$ longer than observed in the test, as shown in Table 5 . It is expected that finer nodalization of the high power channel region of the model would improve the comparison.

Table 5. response characteristics of SEL high power flow instability.

\begin{tabular}{ccc}
\hline & SEL Test 1.1 Case 3 & RELAP5-3D \\
\hline $\begin{array}{c}\text { Amplitude (standard } \\
\text { deviation) }(\mathrm{kg} / \mathrm{s})\end{array}$ & $\begin{array}{c}\text { High Power Channel }=5.7 \\
\text { Low Power Channel }=0.24\end{array}$ & $\begin{array}{c}\text { High Power Channel }=3.5 \\
\text { Low Power Channel = 0.15 }\end{array}$ \\
\hline Period (seconds) & 1.6 & 2.0 \\
\hline
\end{tabular}

Figure 9 compares the experimental (FRT-3-1) and calculated (mflowj 160-01) flowrates for the low power channel inlet line. Again, the response of the code is considered reasonable, although the amplitude was again lower, and the period was longer. Of particular interest is a comparison of the amplitudes of the flow oscillations in the high and low power channels. The high power channel oscillations were larger than the nominal flowrate value, and therefore the high power channel periodically underwent flow reversal. Conversely, the amplitude of the oscillations in the low power channel was insignificant compared to the magnitude of the flow. This disparity in the magnitude of the oscillations clearly demonstrates that the response in the low power channel was sympathetic in nature and did not significantly contribute to driving the instability. The two channels responded differently because of the differences in thermal-hydraulic conditions present. The high and low power channels were geometrically the same, but the heater powers were different by a factor of 20 . Therefore, while two-phase conditions predominated in the high power channel, the low power channel was primarily single-phase liquid. Hence, the oscillations did not occur between the two channels but were instead a system-wide perturbation that involved the high power channel and all the components around the test loop. 
Figure 10 compares the high power channel power in SEL and in the RELAP5-3D calculation. The purpose of this figure is to show the timing of the CHF responses of the heater rod surface temperatures. Initial power level was $3.5 \mathrm{MW}$, ramped to $4.0 \mathrm{MW}$ beginning at 280 seconds, and ramped to $4.2 \mathrm{MW}$ beginning at 345 seconds.

Figure 11 compares the responses of heater surface temperatures in the upper region of the high power channel. As shown, the heaters at locations 1 and 2, near the top of the heated region, entered CHF when channel power was increased to 4.0 MW. The corresponding heater locations in RELAP5-3D model remained wetted until the instability occurred, at $\sim 370$ seconds. A similar comparison is shown in Figure 8 for locations 3 and 4, which are near the middle elevations of the channel. The thermocouple at location 3 entered CHF when channel power was increased to 4.2 MW, and the thermocouple at location 4 entered CHF near the time of onset of the instability. The corresponding RELAP5-3D responses at these locations again showed that CHF was overpredicted compared to the experiment.

\subsubsection{CHF Sensitivity Studies}

Sensitivity calculations were done to investigate the effects of subchannel mixing on CHF and to investigate the importance of CHF prediction on the successful prediction of density wave oscillations. These sensitivity studies involved 1) renodalization and 2) changing the CHF correlation used to predict dryout. The renodalization of the high power channel was done to investigate the effect of channel mixing on CHF prediction, because the rings of heated rods were not uniformly heated. The relative power was 0.65 for the inner six rods, 1.10 for the center twelve rods, and 1.0 for the outer eighteen rods. Also, the bundle can be logically divided into geometrically-similar regions: there are square-pitch subchannels, triangular-pitch subchannels, and subchannels with an unheated wall. Because of the configuration, if subchannel-tosubchannel mixing effects were small, a subchannel with a small relative area could lie adjacent to a heater rod with high relative power, thereby creating a local hot region. The dryout response in this hot region could be significantly different from that in a region with bundle average conditions. Therefore, renodalization sensitivity studies were performed to assess the potential magnitude of these effects. Two configurations were tested.

In the first configuration, the high power channel was renodalized into three radial rings, with no crossflow communication between them. Although this configuration is not realistic, it provided a bounding calculation for the situation of a subchannel that is adjacent to a heater rod with high relative power and that does not benefit from crossflow mixing with its neighbors. This subchannel configuration is shown in Figure 13. With this model, CHF was predicted earlier than in the test. The upper third of the channel with the high powered rods was calculated to be in film boiling at test initiation, at a power of 3.5 MW. In the average and low power channels, CHF was predicted later than in the test at all elevations. There was no change in the prediction of the oscillatory response. A second calculation was made with crossflow junctions at each axial node. One set of junctions connected the inner to the center ring, and a second set of junctions connected the center to the outer ring. Large loss coefficients $(K=100)$ were specified at each junction. Results of the calculation with the crossflow-connected rings were nearly identical to those produced by the original, single channel nodalization. This case shows that CHF will be significantly affected by local subchannel conditions if the fluid is not well mixed.

In the second configuration, shown in Figure 14, the high power channel was renodalized into 
regions of geometric similarity. The configuration tested consisted of three subchannels: one comprised all the square-pitch regions in the channel, the second comprised all the triangularpitch regions, and the third comprised the regions adjacent to the tie rod and pressure tube (i.e. the unheated walls). Subchannel-to-subchannel gaps were modeled using the actual rod-to-rod spacing. This configuration should simulate the actual geometry in sufficient detail to capture the actual mixing between subchannels and to identify locally hotter or cooler regions, if they are present. However, the results using this configuration were not significantly different from those obtained with the single channel model. CHF prediction was not significantly improved, and there was no impact on the prediction of the oscillatory response. This simulation demonstrated that fluid in the bundle was well mixed, and that the single-pipe version of this region of the model was an adequate representation of the high power channel.

A third sensitivity study was done by using the PG-CHF correlation in the simulation instead of the Groeneveld CHF lookup table. The PG-CHF correlation was developed by the Nuclear Research Institute Rez in the Czech Republic, and is based on Czech Republic data for tube, rod bundle, and annulus configurations. This calculation showed significant underprediction of CHF. Film boiling was predicted in the upper half of the channel at test initiation, at a power of 3.5 MW. The oscillatory response was not affected by this study. The result of this study has two implications: first, that the PG-CHF correlation was not appropriate for this bundle, and second, the accurate prediction of dryout was not a major factor in the successful prediction of the oscillatory response.

\subsection{Discussion}

The successful prediction of the density wave oscillations was a direct result of changes that were made to the channel pressure loss distribution in the RELAP5-3D model since the unsuccessful efforts to produce the oscillatory response with the RELAP5/MOD3.2 code. Specifically, a major flow loss that was originally in the high power channel inlet line was moved to the shield plug, in the channel outlet piping. The presence of this major flow loss somewhere in the circuit is required to achieve the overall channel pressure drop shown by the data. The actual location of this major flow loss is somewhat uncertain because no differential pressure measurement is available at the channel inlet.

In the RELAP5/MOD3.2 model, the required conditions of channel flow and total water drum-tosteam drum differential pressure were achieved by adjusting circulating pump speed and the flow area of the channel inlet line control valve. Modeling the channel flow control in this location placed the dominant flow loss of the system at the inlet line control valve. Based on the theory of the density wave oscillation, installing a large pressure loss in the inlet, single-phase region of the channel will tend to stabilize the flow, thereby preventing an oscillatory response from occurring. It is therefore considered implausible that this type of instability could have been achieved in the facility if this major stabilizing effect were present during the test. The key to simulating the instability in the RELAP5 model, therefore, lies in relocating this flow loss to the two phase channel outlet region, where it will reduce the stability of the system rather than increase it. This approach was taken in the RELAP5-3D assessment study.

In the RELAP5-3D model, the dominant system pressure loss was moved from the channel inlet valve to the shield plug in the channel outlet region. The loss at the channel inlet valve was then changed to a value consistent with a fully-open globe valve at that location. This modeling 
change was sufficient to destabilize the system thereby causing it to reproduce the density wave oscillation. Motivation for relocating this loss was based on results obtained with the ATHLET code. It was reported that ATHLET successfully predicted the oscillations, with excellent qualitative as well as quantitative agreement. "This result was achieved by adjusting the DPdistribution along the circuit. This approach was reasonable due to existing contradictions within the given information." 3

The impact of relocating the dominant flow loss on the channel pressure loss distribution shown in Table 6. The dominant flow loss is seen as a shield plug pressure drop of $170 \mathrm{kPa}$ in the RELAP5-3D calculation, compared to $22 \mathrm{kPa}$ in the corresponding location (DRT-5) in the test. Locating the dominant flow loss in the channel outlet region, obviously, removes it from the channel inlet. Therefore, comparison of the channel inlet pressure drop information should be done to determine whether the channel outlet location is appropriate for this flow loss.

Unfortunately, this instrument was not present in the test facility, so the required comparison cannot be made.

Table 6. SEL and RELAP5 differential pressures.

\begin{tabular}{llccc}
\hline Location & Instrument & Test 1.1 Case 3 & RELAP5/MOD3.2 & RELAP5-3D \\
\hline $\begin{array}{l}\text { HPC Lower } \\
\text { Region }\end{array}$ & DRT-2 & $>50^{2}$ & 60 & 55 \\
\hline $\begin{array}{l}\text { HPC }{ }^{1} \text { Upper } \\
\text { Region }\end{array}$ & DRT-1 & 15 & 15 & 12 \\
\hline HPC $^{1}$ Total & DRT-3 & 70 & 75 & 67 \\
\hline HPC ${ }^{1}$ Outlet & DRT-4 & -2 & 9 & 7 \\
\hline Shield Plug & DRT-5 & 22 & 22 & 170 \\
\hline Horizontal Outlet & DRT-6 & 33 & 26 & 24 \\
\hline $\begin{array}{l}\text { Water Drum-to- } \\
\text { Steam Drum }\end{array}$ & DRT-SW & 330 & 290 & 280 \\
\hline
\end{tabular}

Notes: 1. HPC - High Power Channel

2. Reading offscale

There was significant justification for relocating a major pressure loss from the channel inlet to the outlet region. First, there were large uncertainties associated with the actual pressure loss distribution around the high power channel. Of major concern is the lack of single-phase data that is necessary to adjust the form losses in the various regions of the RELAP5 model. There were no single phase data available for the high power channel instrumentation, and for the low power channel, which was geometrically similar but primarily operated in single phase conditions, there was no known instrumentation available.

Second, there was no differential pressure measurement between the water drum and the channel inlet. This measurement must be inferred from the remaining instruments. Therefore, the actual losses across the valve at the channel inlet were unknown. Further, the differential pressure measurement for the lower half of the heated region was offscale high during the test. It is also not known whether the differential pressure measurements in the channel outlet region were accurate, and without the water drum-to-channel inlet differential pressure measurement, there 
was no means to check for data consistency by summing the measurements around the loop. Also, no instrument uncertainty information was available, so there was no means to determine the expected accuracy of the data.

Two additional differences were present between the model used for the RELAP5-3D assessment of the High Power Flow Instability Test and the model used for assessment of RELAP5/MOD3.2. First, the EPRI interphase drag model was used in the heated rod bundles, instead of Bestion interphase drag, which was used in the RELAP5/MOD3.2 assessment. The EPRI correlation is the default bundle model in both versions of the code, and it is the model recommended by the RELAP5 user guidelines. It was determined that the high power flow instability could not be reproduced with the Bestion correlation.

Second, input model changes were made to the values of the local boiling factor K5, which is used with the Groeneveld CHF correlation. Recall that, in the HTL Critical Power Test RELAP5/MOD3.2 assessment, the K5 factors were used to simulate hot channel factors that compensated for perfectly-mixed fluid in the model of the high power channel, a consequence of the single-pipe nodalization. However, the channel nodalization sensitivity study, discussed in Section 3.2.3, determined that the single-pipe representation is appropriate, and that overprediction of subchannel mixing effects is not an issue. Also, application of the K5 factors in this manner is not consistent with the intended usage in the published correlation. ${ }^{4}$ Therefore, in the SEL High Power Flow Instability Test RELAP5-3D assessment, the K5 factors were applied as corrections to the local heat flux so that the heat flux value supplied to the CHF correlation is the "average heat flux from the start of boiling". This application of the K5 factors is consistent with the intended use as specified in the published correlation. This change did not make a significant difference in the prediction of $\mathrm{CHF}$

\section{CONCLUSIONS}

The results showed that the RELAP5-3D predictions were nearly identical to the RELAP5/MOD3.2 assessments for the major phenomena associated with RBMK transient analyses. RELAP5-3D was capable of representing CCFL, break flow rates, manometer oscillations, flow pattern-induced oscillations, and other RBMK phenomena.

The results also demonstrated that RELAP5-3D has the capability to predict the density wave oscillations. The oscillations predicted by the code were similar in magnitude and frequency to the response observed in the experiment. However, to obtain this result, the majority of the friction pressure losses must be located in the two-phase channel outlet region. When this was done, the pressure drop across the channel outlet, in the shield plug region, was significantly higher than shown by the data, although the water drum-to-steam drum pressure drop is in agreement with the data. Justification for the presence of a significant pressure drop in the outlet of the channel was present. Major uncertainties are associated with the pressure loss distribution around the high power channel. Additionally, friction loss characteristics of the shield plug, which is in the channel outlet region, were not known. No means was available to check the differential pressure instruments for consistency. Therefore, was is difficult to draw firm conclusions about the differential pressure data with a high degree of confidence. These uncertainties lend credibility to the modeling techniques used to reproduce the density wave oscillation phenomenon in the RELAP5 model. Finally, adjusting the pressure loss distribution around the high power channel appears to be consistent with the method used to achieve the 
oscillatory response using the ATHLET code.

The CHF model needs improvement, although the prediction of dryout was a negligible contributor to the prediction of the density wave oscillations. When the Groeneveld CHF table lookup model was used, the severity of conditions required to exceed CHF were consistently higher in the calculation than in the experiment. On the other hand, the PG-CHF correlation predicted CHF occurrence at conditions much less severe than in the experiment. According to the channel nodalization studies, the ability of RELAP5-3D to predict density wave oscillations was not sensitive to subchannel mixing effects. Despite the lack of agreement in the heater surface temperature responses, the RELAP5-3D model still reproduced the oscillations. Therefore, the prediction of critical heat flux was of minor significance in the calculation of the instability phenomenon. The major conclusion was that RELAP5-3D has the capabilities to properly represent RBMK phenomena.

Axial nodalization studies have not been done for the High Power Flow Instability Test. However, finer axial noding in the high power channel may improve the prediction of CHF. It may also further improve the agreement of the density wave oscillation response predicted by the code. 


\section{REFERENCES}

1. Richard T. Pagh and Bruce E. Schmitt, Code Validation of RELAP5/MOD3.2 for the RBMK Reactor Design Using SEL and HTL Experimental Data, RELAP5 International Users Seminar, College Station, Texas, July 17-21, 1998.

2. : H. Mochizuki, Density Wave Oscillation Beyond Dryout under Forced Circulation and Flow Pattern Induced Oscillation under Natural Circulation, Annex 1 p. 5, Report of the Consultants Meeting on Code Validation for RBMK LOCA Analysis, Vienna Austria, 16-22 February 1998, RBMK-SC-56,18 March 1998.

3. Report of the Consultants Meeting on Code Validation for RBMK LOCA Analysis, Vienna Austria, 16-22 February 1998, RBMK-SC-56,18 March 1998, p. 10

4. D. C. Groeneveld, S. C. Cheng, and T. Doan, 1986 AECL-UO Critical Heat Flux Lookup Table, Heat Transfer Engineering, Vol. 7, nos. 1-2, 1986, pp. 46-62. 


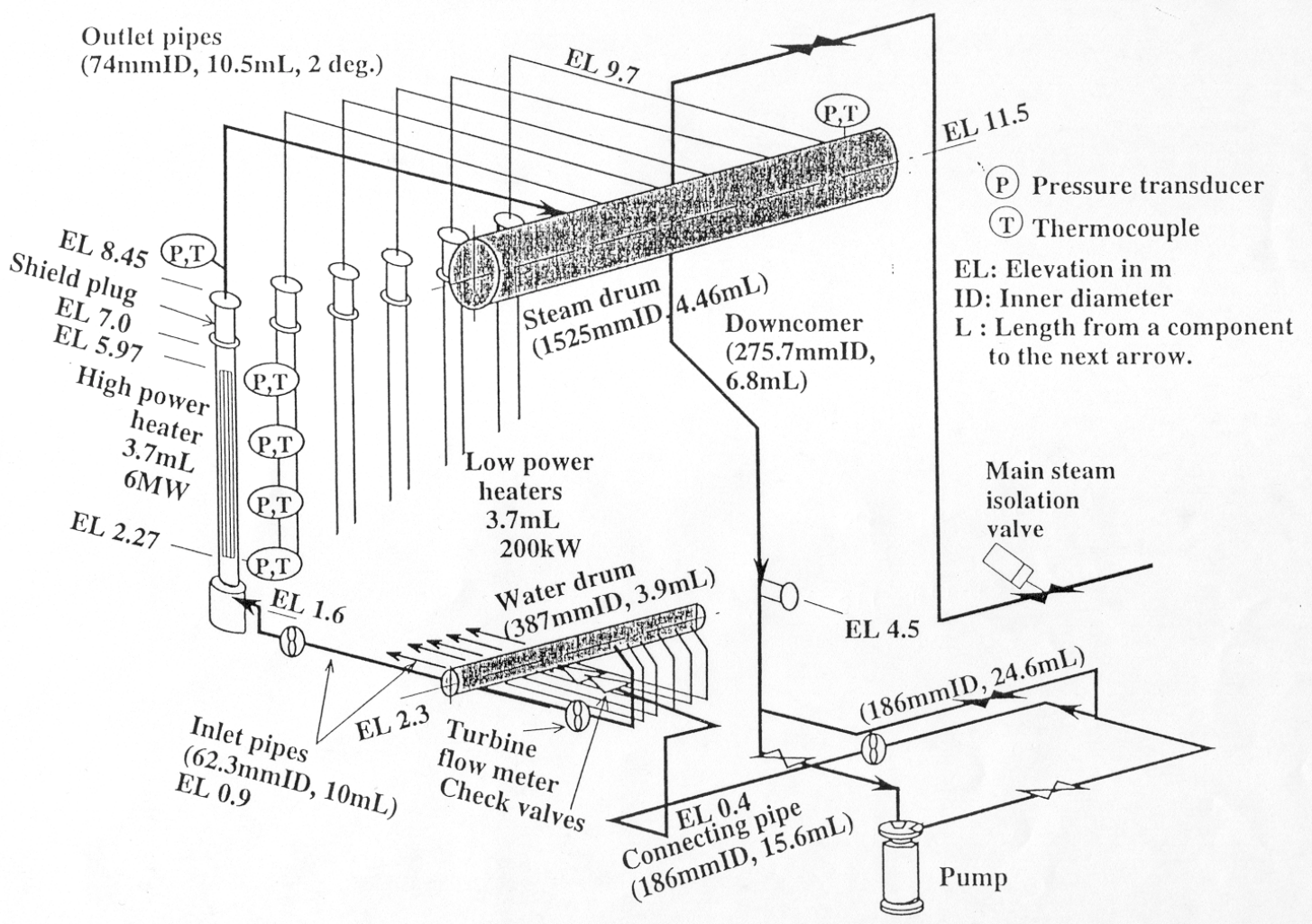

Figure 1. Schematic of Safety Experiment Loop (SEL) facility

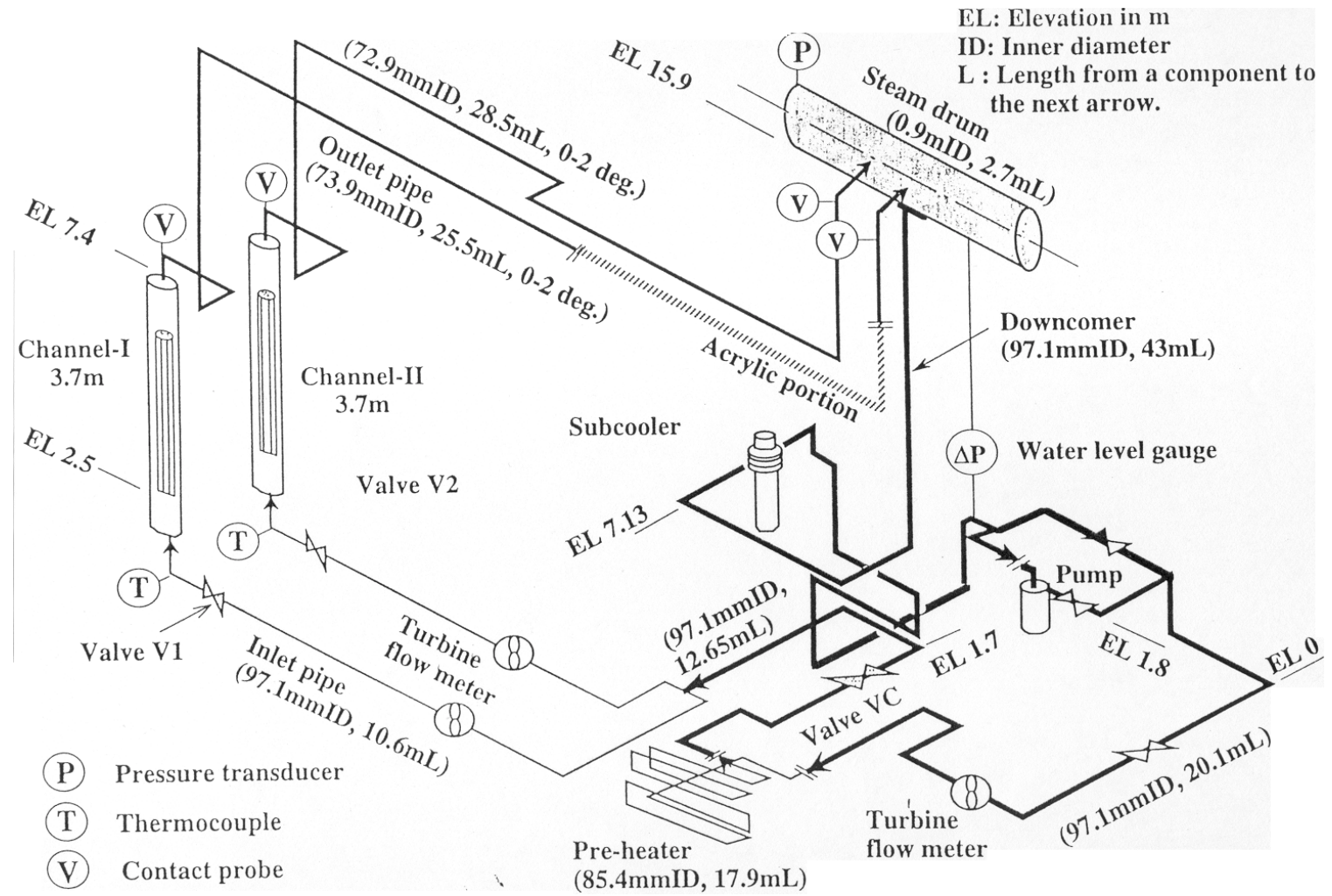

Figure 2. Schematic of Heat Transfer Loop (HTL) facility 


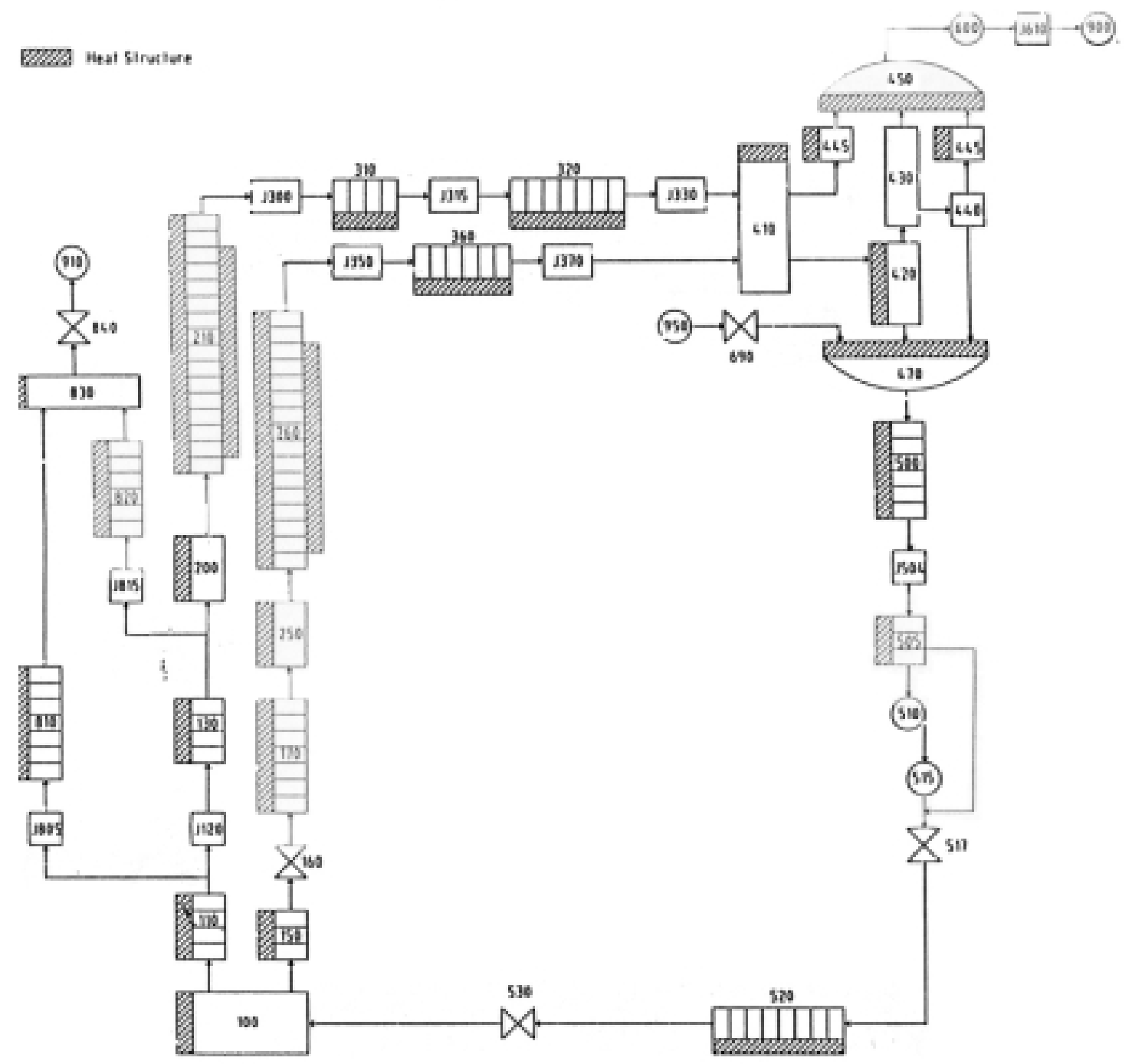

Figure 3. RELAP5 nodalization diagram of SEL facility 


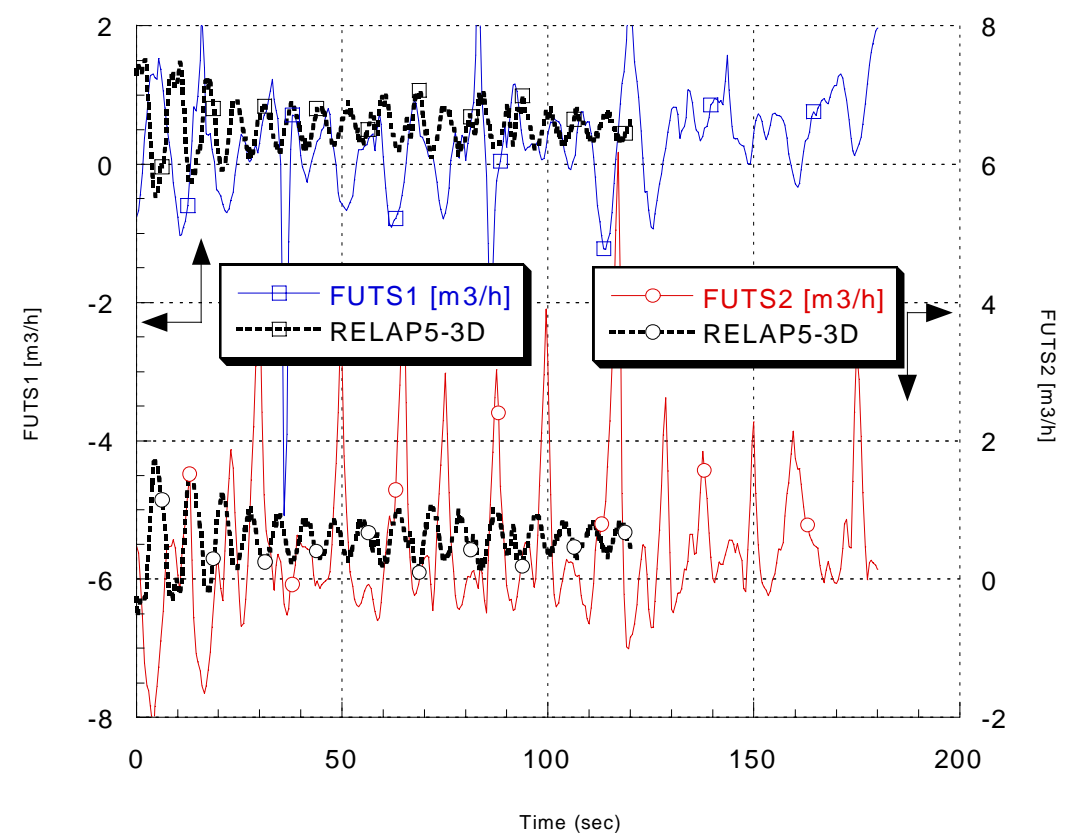

Figure 4. Flow fluctuation in HTL at low water level conditions.

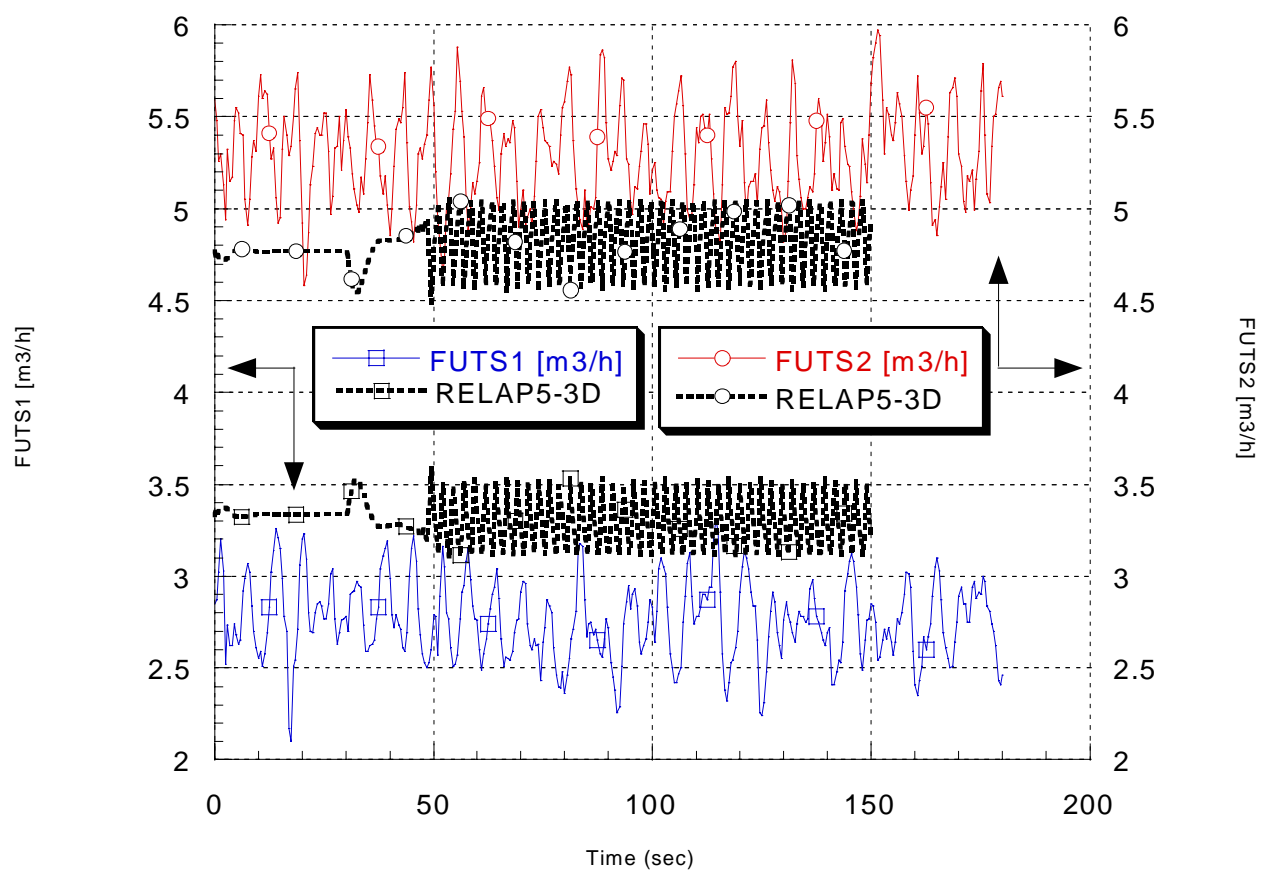

Figure 5. Flow fluctuation in HTL at normal water level. 


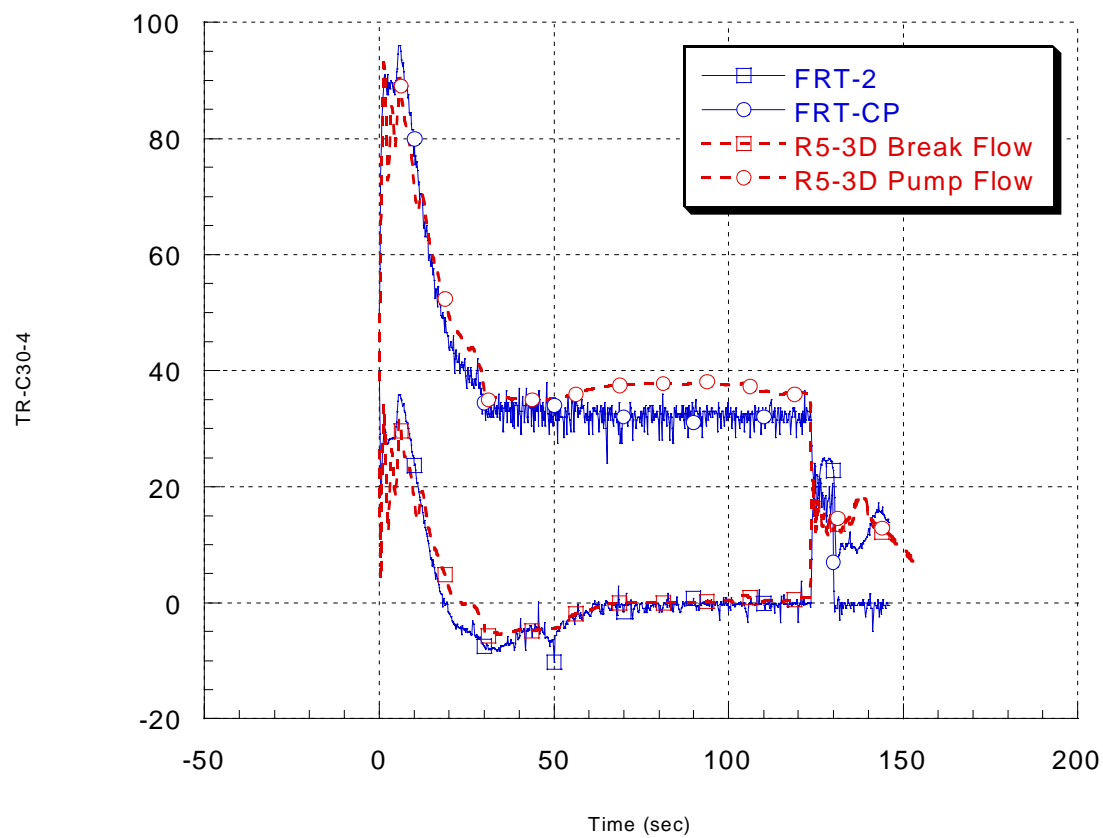

Figure 6. SEL flow responses during inlet pipe rupture test.

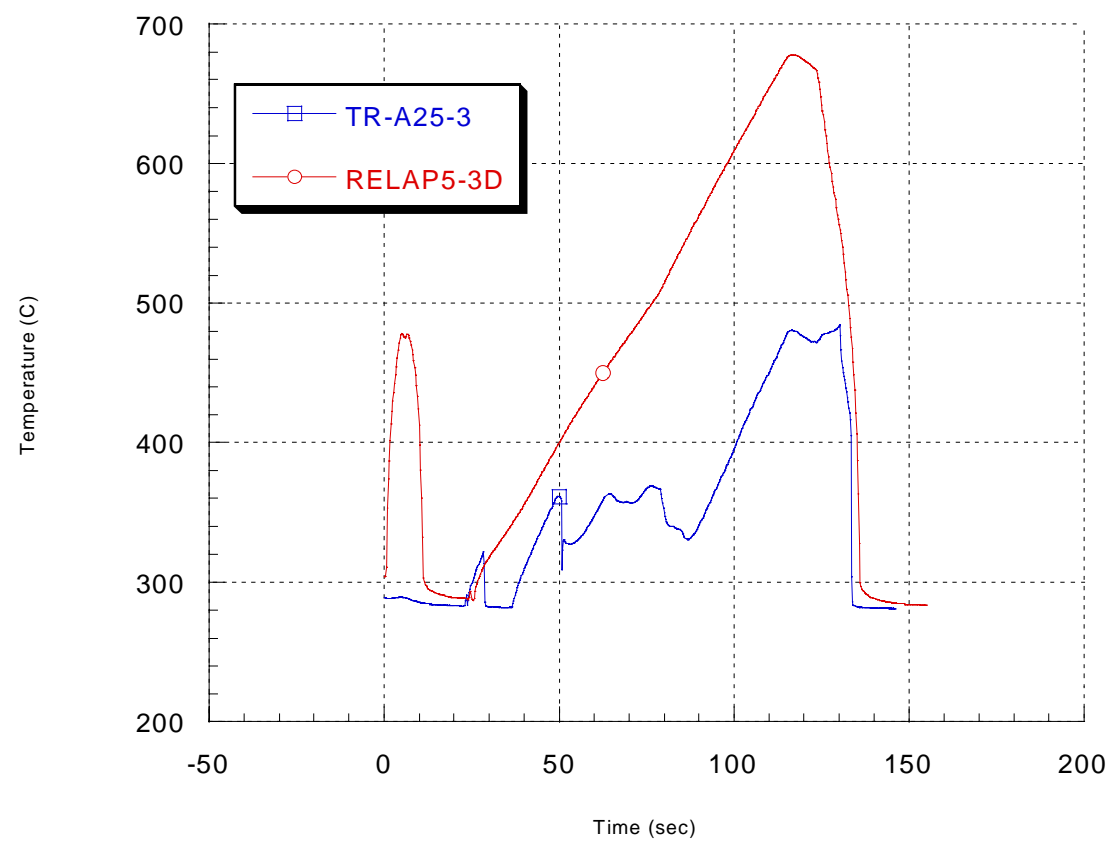

Figure 7. SEL heater rod surface temperature at elevation 3 during inlet pipe rupture test. 


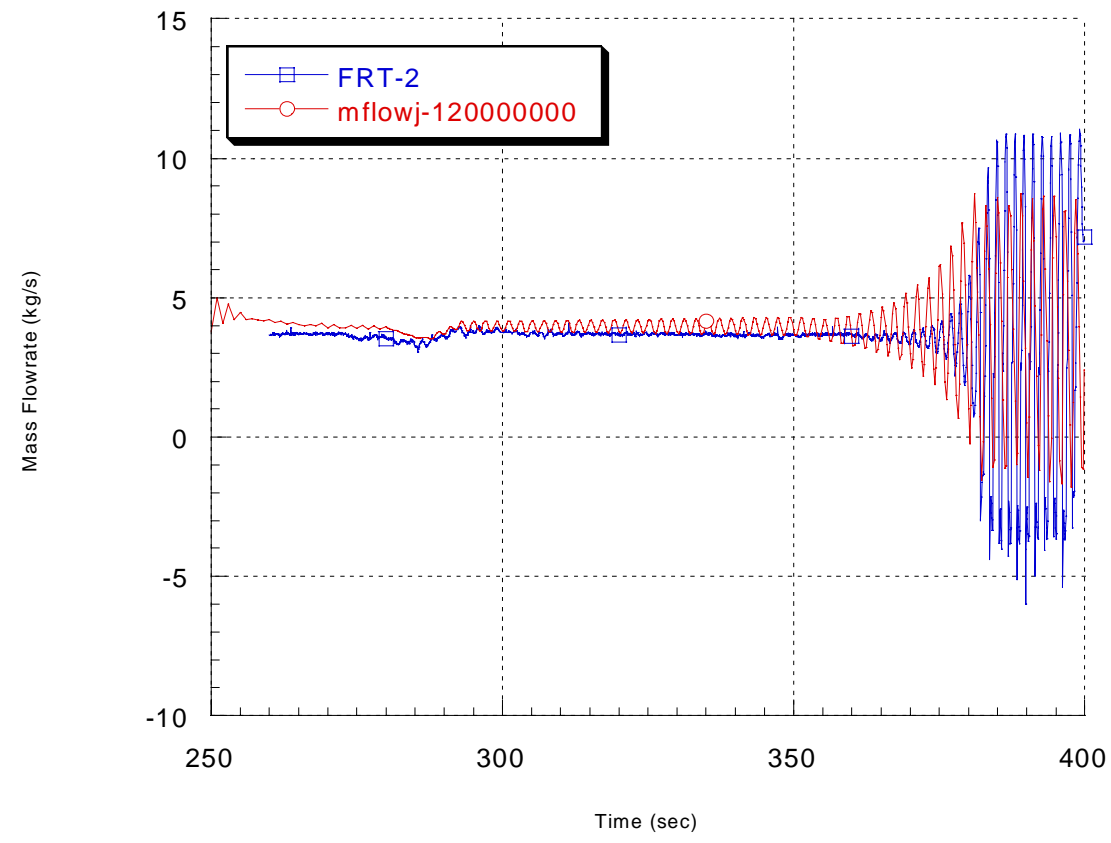

Figure 8. SEL and RELAP5 high power channel flowrates during high power flow instability test.

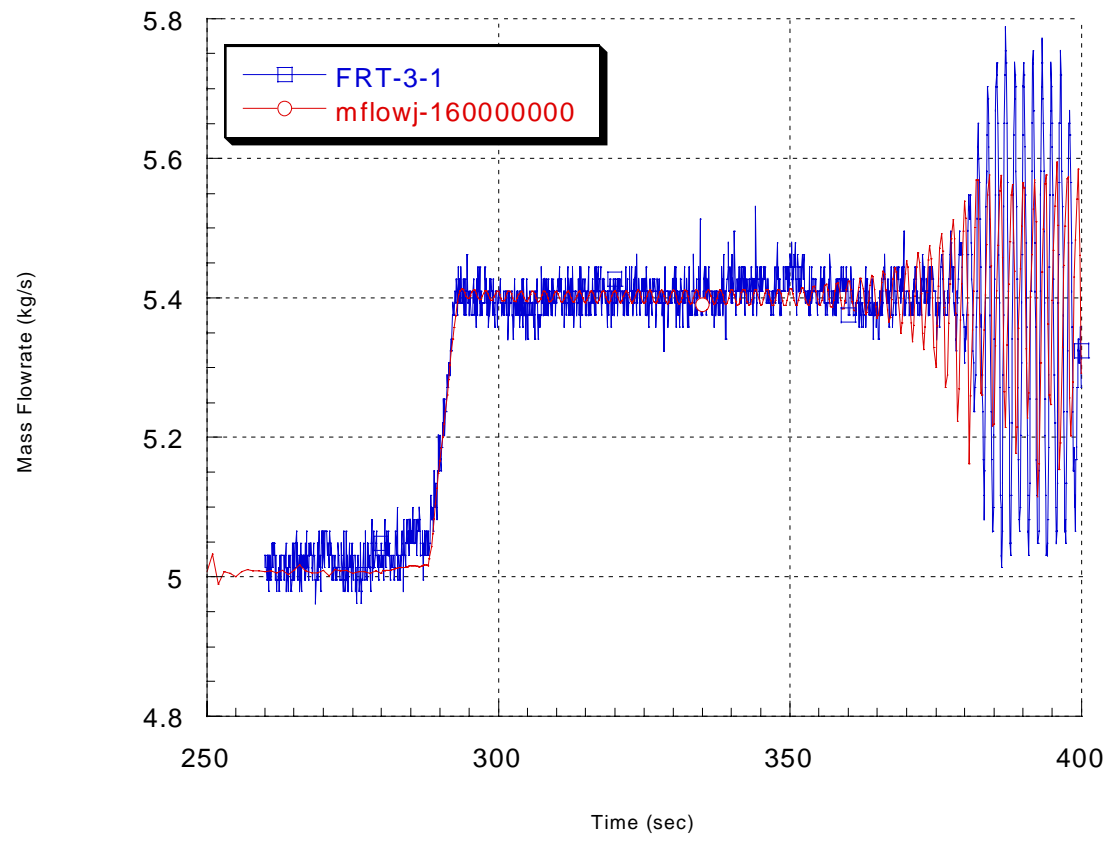

Figure 9. SEL and RELAP5 low power channel flowrates during high power flow instability test. 


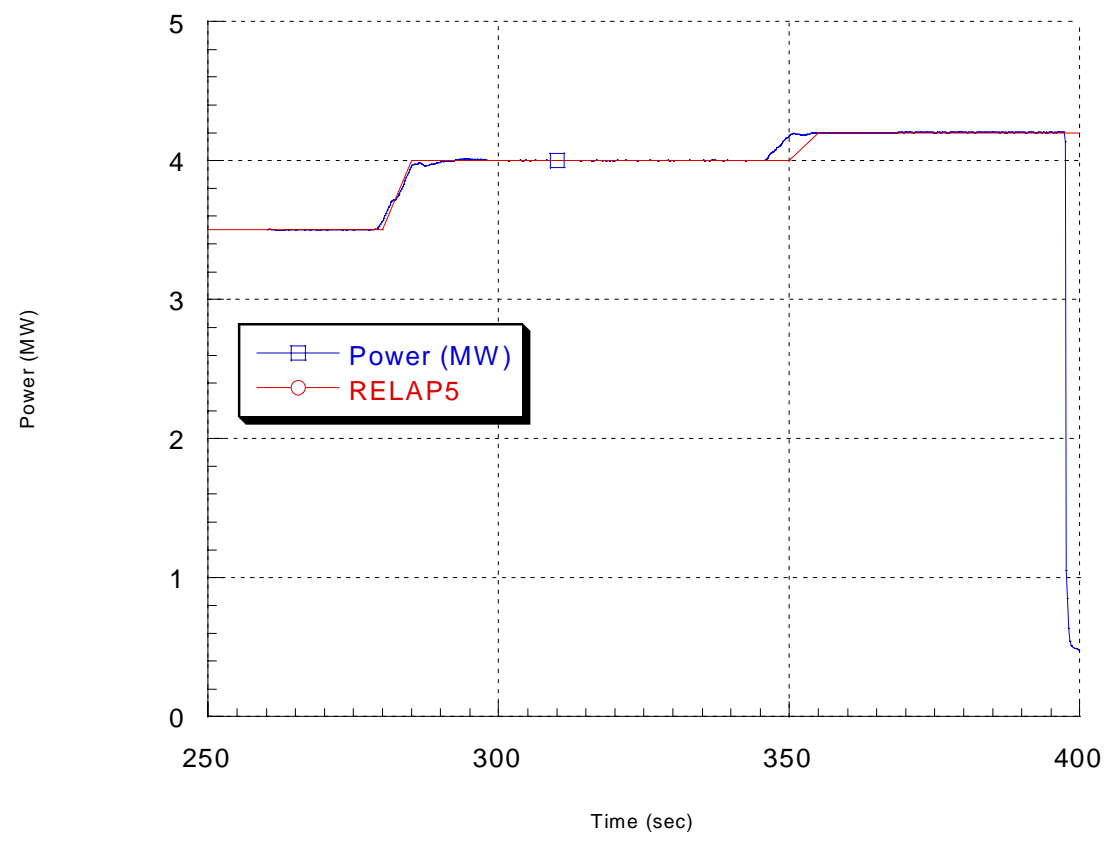

Figure 10. SEL and RELAP5 high power channel power during high power flow instability test.

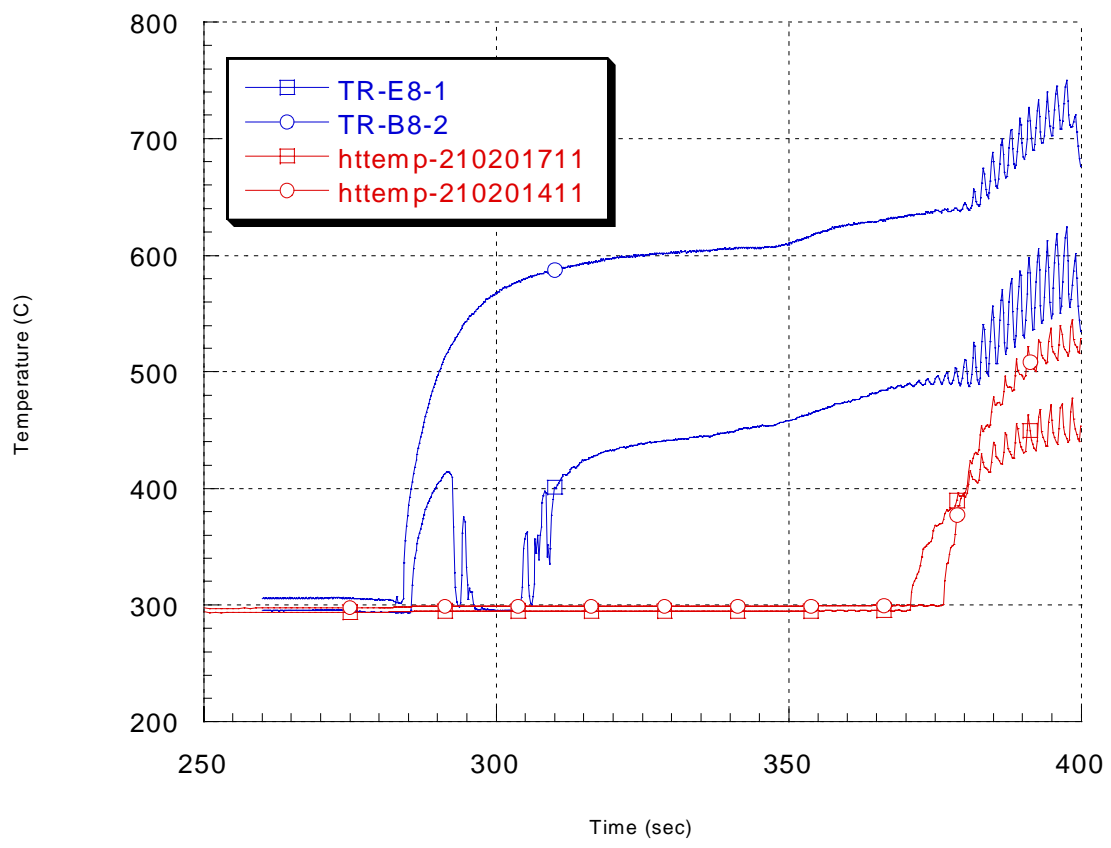

Figure 11. Heater rod surface temperatures in upper region of high power channel during high power flow instability test. 


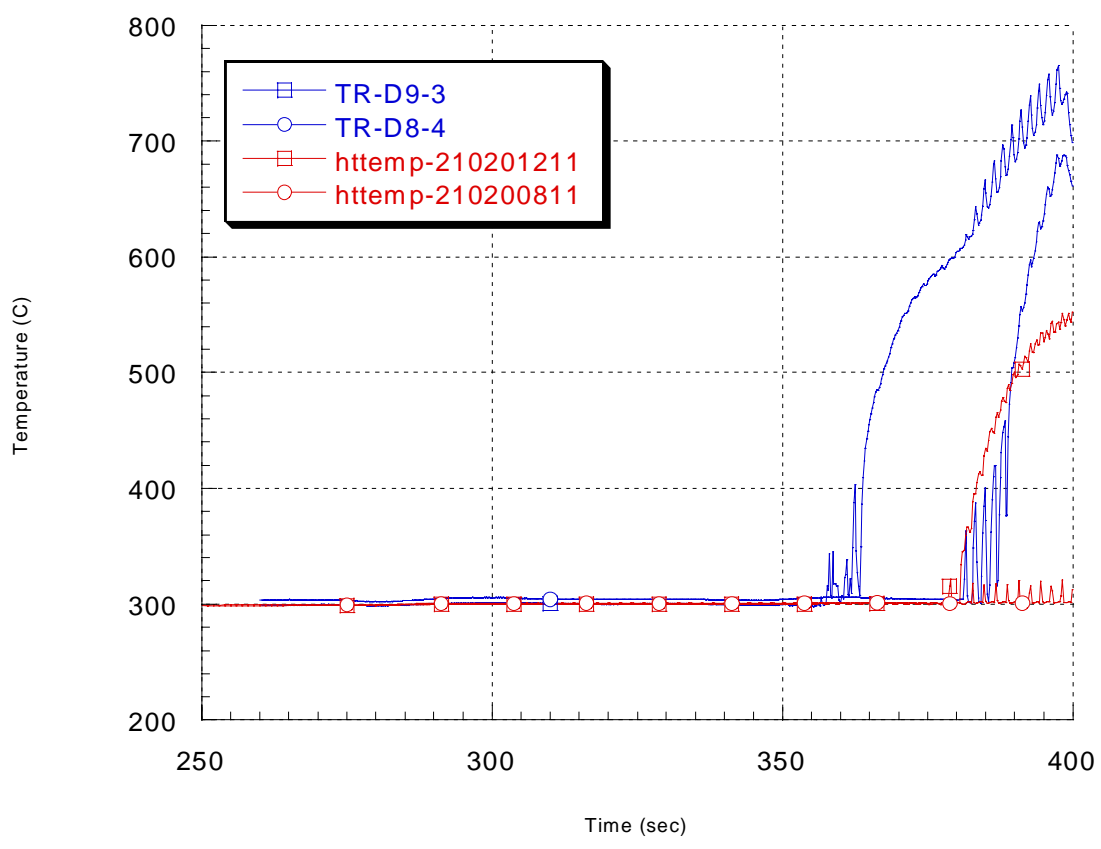

Figure 12. Heater rod surface temperatures in middle region of high power channel during high power flow instability test.

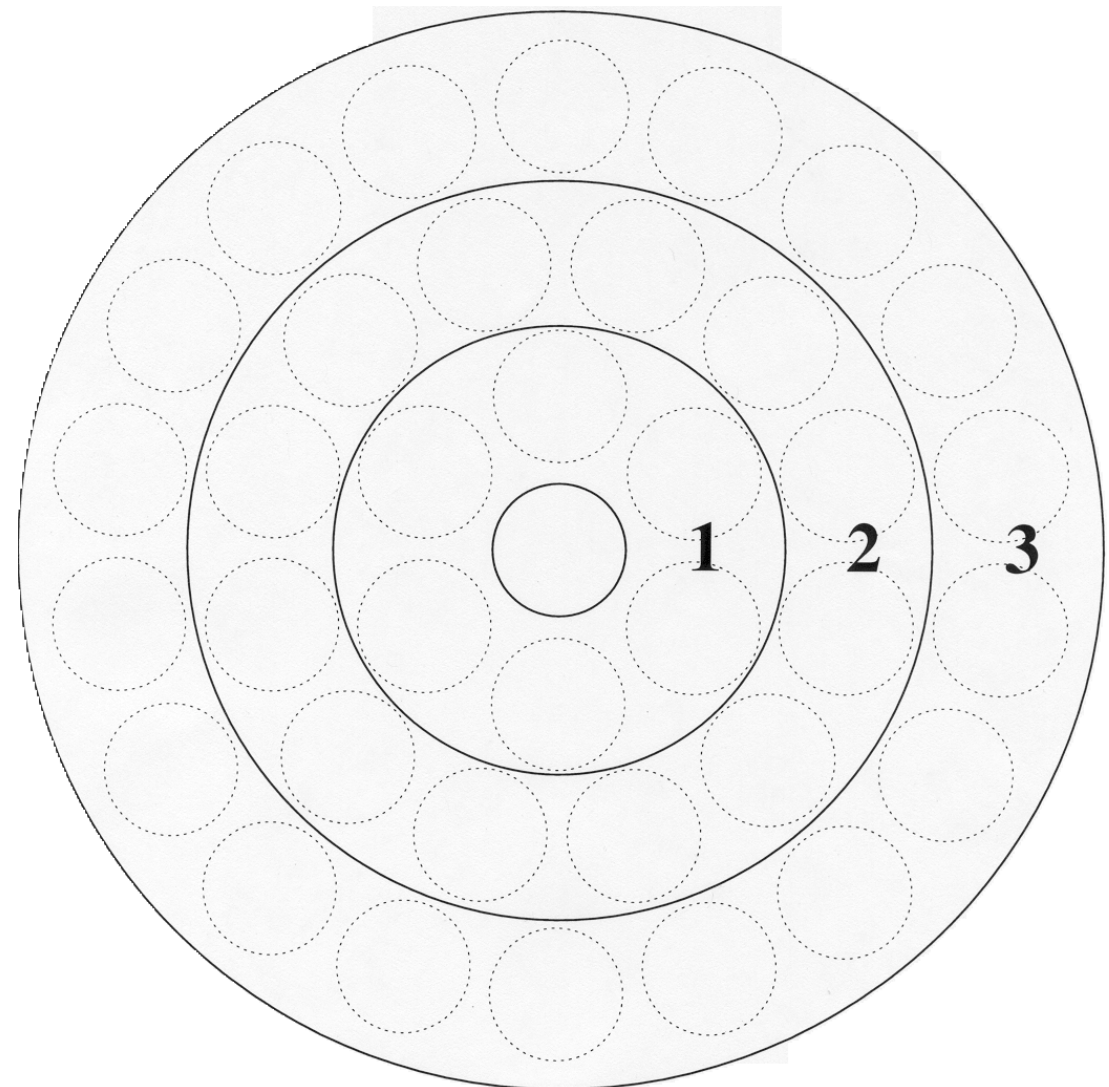

Figure 13. SEL RELAP5 high power channel rod bundle radial ring nodalization. 


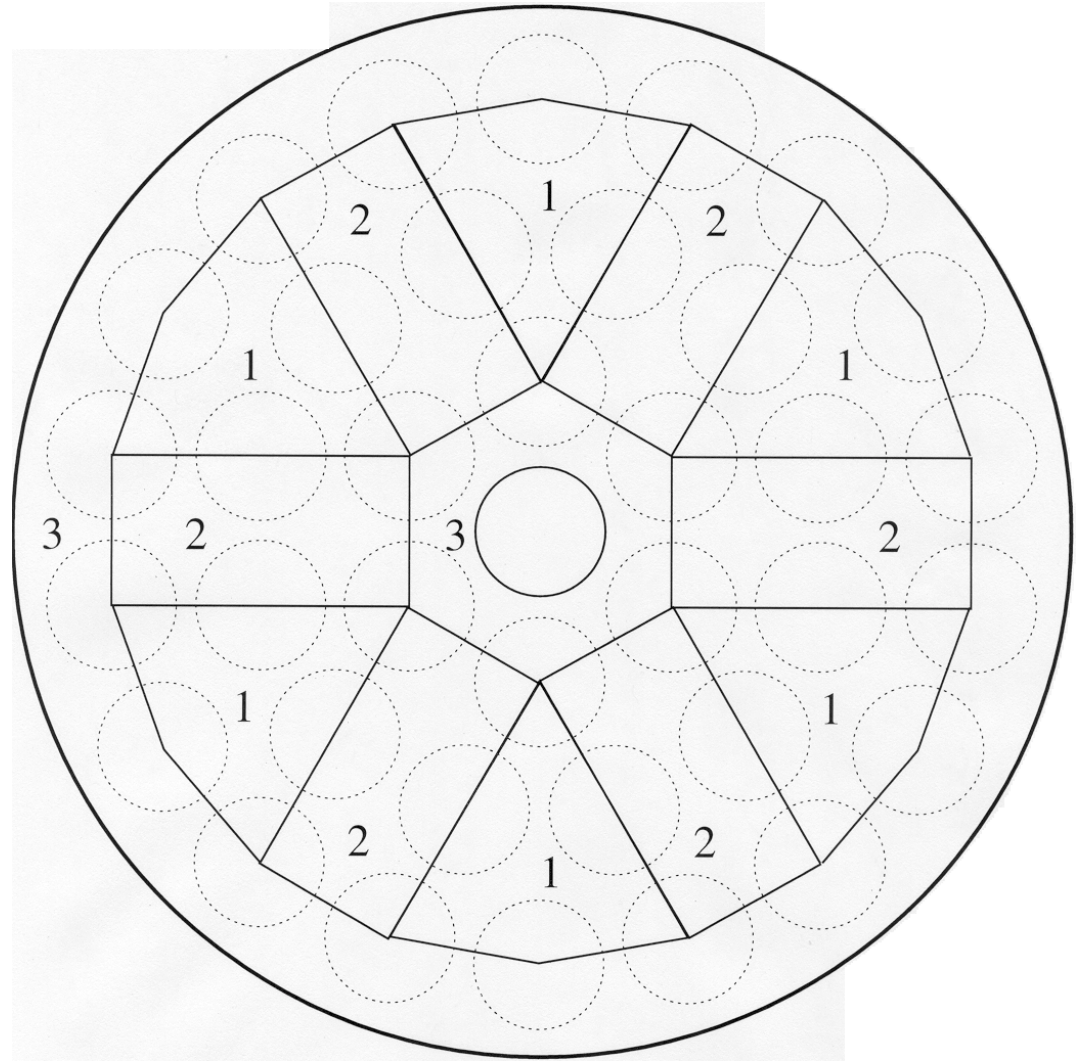

Figure 14. SEL RELAP5 model high power channel nodalization by geometric similarity 